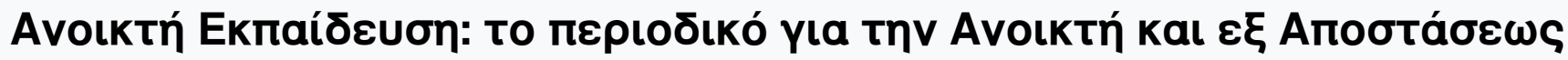

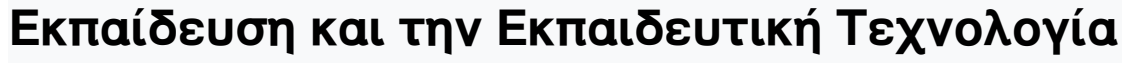

Tóp. 4, Ap. 1 (2008)

\section{Open Education}

The humal ik Open and Dthance Education and Educational Tequnstory

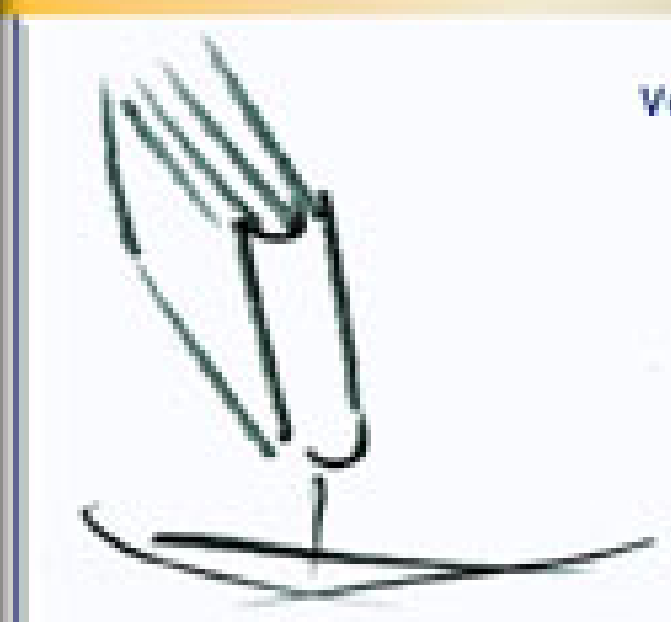

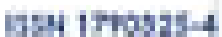

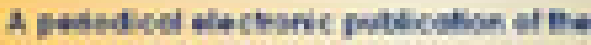

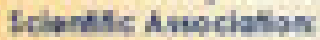

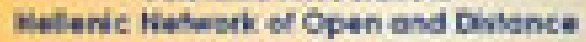
Id ecation
Critical issues in the Supervision of Post-Graduate Dissertations in Distance Education Environments

Kofi Poku Quan-Baffour, Maurice Taonezvi Vambe doi: $10.12681 /$ jode. 9728

Volume 4

issue 1 2005

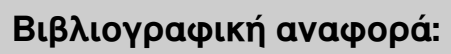




\title{
Critical issues in the Supervision of Post-Graduate Dissertations in Distance Education Environments.
}

\author{
Dr Kofi Poku Quan-Baffour \\ Senior Lecturer \\ Institute for Adult Basic Education \& Training \\ University of South Africa \\ PO Box 392 \\ Pretoria 0003 \\ e-mail:quanbkp@unisa.ac.za \\ Dr Maurice Taonezvi Vambe \\ Senior Education Consultant \\ Institute for Curriculum and Learning Development \\ University of South Africa \\ P O Box 392 \\ Pretoria 0003 \\ e-mail:vambemt@unisa.ac.za
}

\begin{abstract}
.
The main aim of this paper to identify, explain and advance as best practice, the principles of an alternative framework of postgraduate supervision in the context of distance education. This framework, we describe as Dynamic facilitation. The paper starts with a critique of the African Union Commission Plan of Action of the Second Decade for Education in Africa (2006-2015), highlighting the document's unfortunate silence on the role of distance education in Africa's Higher education. We suggest that this silence is due to African educationists' reliance on old theories of learning and supervising dissertations whose main limitations are their narrow definition of higher education as residential university, and also the dominance ascribed to the pedagogic role of supervisors in the Behaviourist and Cognitive theories of learning. We critique these theories for their inherent limitations and proceed to suggest that the context of distance education has its unique features and particularities that must be robustly engaged with, in the areas of learning and supervising of postgraduate dissertations. We then propose 'dynamic facilitation' as a type of supervision suited to distance education contexts. Our basic argument is that dynamic facilitation empowers postgraduate students because it allows for their initiative in generating new knowledge systems. We conclude by suggesting that dynamic facilitation takes into account the 'distance-ness' between supervisor and the supervised; it integrates methods of assessment ranging from the main dissertation, to continual self-reflective assessment achieved through maintaining journal notes on work done and portfolio of the supervised's experience during the process of supervision.
\end{abstract}

Key words: Supervision, Distance Education, Post-Graduate, Critical, Dissertation, Context, Dynamic facilitation. 


\section{Introduction}

\section{Post Graduate Supervision as Assessment in the Context of Distance Education}

The Plan of Action of the African Union Commission (AUC) on the Second Decade of Education for Africa (2006-2015) adopted in 2006 in Maputo considers higher education as a priority investment and growth area (AUC: Plan of Action: 2006). The Plan of Action lists the following seven areas for its development focus; Gender and Culture, Educational Management Information Systems, Teacher Development, Higher education, Technical and Vocational Education and training, Curriculum Development and Related Issues of Teaching, and Learning Materials and lastly, Quality Management (AUC Plan of Action.2006: I ). Unfortunately, within the area of Higher education as contained in the Plan of Action there is deafening silence on distance education. Higher education is narrowly defined as residential university education.

In other words, the AU Commission Plan of Action drawn out for the continent ironically marginalizes distance education when this sector is actually growing rapidly in Africa, following the failure of residential universities to absorb all potential African learners. At a stakeholder workshop on harmonization of Africa's higher education organised by the African Union Commission and hosted by the Association of African Universities on the $7^{\text {th }}$ and $8^{\text {th }}$ of May 2007 under the title of "Developing Pan African Quality Rating Mechanism," (Butcher:2007) one of the organisers reports that education experts from Africa were quick to point out that the quality rating mechanism submitted to them by the AU Commission for consideration, did not sufficiently address the unique challenges of Distance Education as one amongst many, institutions of Higher Education in Africa. The experts bemoaned the fact that there is not awareness in institutions that claim to speak for Africa on the particularity and unique context of distance education that the experts characterised as being defined by several factors, the following being the most important;

- Distance between learners and the physical infrastructures from the universities of where students have enrolled.

- Nature of mode of delivery in which in distance education there is minimum contact between learner and teacher and the textbook is taken as the substitute for the teacher in the residential university.

- Flexibility of times when student assessment can be conducted

- Untraditional modes of examinations, where students can submit portfolios of their work as an add-on to sitting examinations.

- Supervision or assessment procedures where in Distance Education emphasis is placed on continual self-evaluation as opposed to a once-off examination that is usually conducted at the end of each semester or year in a residential university (Criteria for Quality Distance Education in South Africa - Draft Policy Statement, 1998: 1-21).

\section{Behaviourist Theories of Postgraduate Supervision in Distance education Contexts}

These above factors have serious consequences on the specific nature of supervising postgraduate students in the sense that in Distance Education the student is writing a thesis in isolation, sometimes after long hours at work. The problem is that some lecturers and educationists at Distance Education institutions have continued to supervise distance education students as if they are at a residential university. For example, an analysis of a sample of some "types of supervisions" 
shows that these are still informed by outdated learning theories. There is not critical rethinking of the notions of 'supervision,' 'supervisor,' 'supervisee,' knowledge expert' in the Behaviourist, Cognitivist and Constructivist theories of learning and supervision.

Behaviourist theories developed between 1800s and early 1900s emphasis conditioning students to respond to research stimuli created by the teachers (Pavlov ). As understood by Thorndike the Law of Effect in behaviourist theories of education state that if an act is followed by a satisfying change or reward in the environment there is more likelihood that it would be repeated in a similar situation (Slavin, 2006:136). There is no denying that any theory of education is needed to help explain and then transmit relevant knowledge and skills to the young to enable them take their respective adult roles in the society.

However, Behaviourist theories can promote undemocratic practices in the relationship of students and teachers in the context of supervision. For example, Bishop \& Glynn 1999 correctly note that conditioning students to stimuli provoked by teachers always imply a relation of power in which the power to name reality resides in, is dominated by, and invested in the teachers who are described as 'supervisors' and 'knowledge experts.' The Shorter Oxford English Dictionary on historical principles (1944) describes a supervisor as one who 'looks over, inspect, oversee and generally gives 'direction or control over business; an overseer' (Little etal 1944: 2085). Each of those verbs vests the supervisor with extraordinary authority that leaves little space for the one who is being supervised to exercise initiative and have meaningful input in the process of writing up a thesis. When behaviourist theorists of education further describe the supervisor as 'knowledge expert' (Little, 1999:656) a certain cultism, and secrecy is conferred on the expert to speak on behalf of somebody, a process that can displace the voice of postgraduate students in learning and research.

In its traditional sense then, when the behaviourist theory of learning is transposed to supervising, the theory promotes a type of supervising that one can described as the dominant paradigm. Freire (1970) as restated by Spener (1990:2) has called this phenomenon, the banking concept of education because the supervised is considered an empty vessel that has to be filled with knowledge from the teacher. That knowledge originating from the teacher to the supervised student involves not only information on correct formats of presenting thesis; sometimes the supervised are instructed on what to research on, how to argue and arrive at apriory conclusions. At its worst, Behaviourist theories can promote a clientile or patronage type of supervision. This type of supervision relies on ideological loyalty to the supervisor, without which the supervised would not successfully complete a thesis project (Vambe 2005).

\section{Cognitivist Theories of Postgraduate Supervision in Distance Education Contexts}

Cognitive theorists of learning are also blighted by the perception of students as receiver of knowledge and not generators of knowledge. Cognitive theorists emphasise psychological entities as knowledge, conscious, intelligence, thinking, imagining, creating, generating plans and strategies related to reasoning and problem solving (Flavel, Miller and Miller, 1993 :3 ). In the theory, meta-cognition is heavily reliant on active monitoring and consequent regulation and orchestration of the process of supervising in relation to some concrete goal or objective (Dembo, 1994:96). 
As explained in the cognitive approach the amount of supervision depends both on how teachers present materials to students and on how the student processes it. Here, a residual element of Behaviourist theorists is implied because the instrument of cognition are developed and provided by the supervisors. There is a mistaken belief in cognitive theories that research problems for postgraduate students emanate from the mind. This result in students concentrating post-graduate research on issues that are not of direct relevance to their communities. Each time a post-graduate researcher is implicitly or explicitly forced to research on a 'donated' area, it is a violation of the respect that must be accorded to postgraduate researchers as people with a capacity to generate knowledge that might even contradict the perspectives of their mentors. The research questions that fire the passion of student researchers are better left to the students.

In short, cognitive theorists of supervision can entrap post-graduate students in the sense that areas of research are divorced from social reality, interpretation of facts are often rendered too subjective and theoretical approaches are sometimes used to confirm existing ways of doing things ( Dembo, 1994: 102). To critique Behaviourist and Cognitivist theories of supervision in this fashion is not to minimize the potential of experts who use them to authorise deeper supervising approaches. It is to argue that the supervision of postgraduate studies is rendered poor when the aim is to confirm the conclusions of previous experts. Since the main reason for undertaking postgraduate research work is to seek to originate new forms of knowledge the force of this intellectual enterprise derives from post-graduate students' capacity to question received assumptions embedded in previously studied social, economic, cultural and political concepts and ideas.

\section{Constructivist theories of supervising post-graduate dissertations.}

In order to avoid the limitations of traditional theories of supervising postgraduate students, educationists have proposed the use of constructivism. Its assumptions are that human beings construct knowledge based on an understanding of human experiences (Confrey, 1990:108). The constructivist theorists acknowledge the fact that human beings' picture of the world is not static because their conceptions are subject to change. However, if a student merely repeats what the teacher or the text book has said, this is of course no indication of a conceptual growth in postgraduate research work (Von Glaserfeld,1992:32). Instead, constructivists argue that for students to really understand and be able to apply knowledge they must work or solve problems. In this way they can discover things for themselves. Students must construct knowledge in their own minds. Human beings are able to be aware of their constructed knowledge and can modify this knowledge in the light of new facts that have been discovered through processes of conscious reflections on that constructive process (Slavin, 2006: 243).

Confery (1990:115) adds that a significant improvement in student learning depends on a fundamental shift from teacher to student responsibility for, and control over research. Post-graduate research and supervision should therefore encourage the development in students relevant skills for effective and powerful constructions of their experiences. Students discover and transform complex information, and through this process make research problems, processes and findings their own. Because of the emphasis on students as active learners constructivist strategies are often called student-centred instruction ( Slavin,2006:243).

Constructivist theories of supervision have not escaped the criticism that they tend to assume that students have all the intellectual resources to construct their 
meanings at will. This criticism is valid because post-graduate supervision is a mutual process of give and take. Both the supervisor and the supervised are active agency in generating knowledge that each of them has to respect, irrespective of ideological difference or differences in theoretical approaches each works with.

\section{Social Constructivism and Dynamic facilitation as Best practices of postgraduate Supervision}

When placed against the limitations of post-graduate supervision informed by and embedded in the theories of Behaviourism and Cognitivism, we in this paper have tended to gravitate towards the theory of social constructivism. In line with the need to devolve power to the supervised, and generate knowledge of a higher level, and one that furthers the intellectual growth and development of the student in the process of conducting a post-graduate research project, we propose dynamic facilitation as the best practice in supervision. Little (1944: 197) and his fellow researchers suggest that dynamic facilitation promotes the supervised as the main actor in research project. $\mathrm{He} / \mathrm{she}$ decides the research problem drawn from real life situations.

Dynamic facilitation emphasises the role of the institution where post-graduate students are enrolled as that of providing necessary study infrastructure such as libraries and clarifying channels of communication between the researcher and facilitator. We are aware, as Bishop and Glynn (1999) are, that every act of facilitation and promoting post-graduate research work necessarily implies some 'authoritative' voice that guides and mentors the one whose ideas are being promoted (Bishop \& Glynn 1999).

This is important to state in order to avoid giving the impression that in dynamic facilitation there are no rules to be followed. For instance, our understanding of dynamic facilitation also implies recognising that any institution of higher learning follows a particular research proposal framework. This is a technical dimension of research and supervising which has to be enforced whether one is a supervisor or facilitator. The framework of research proposal at postgraduate level is an established format and the researcher has unfortunately, no power to alter it. Dynamic facilitation recognises that the supervision of post-graduate work is an opportunity of personal intellectual growth. That growth is not complete without ideological contestations of, and with received forms of knowledge.

\section{Pedagogical Elements of Dynamic Facilitation in the context of Distance Education}

There are three main aspects that form the foundation of dynamic supervision of postgraduate dissertations in the context of Open and Distance Learning. The first aspect is the necessity for introducing learner-centred approaches to post graduate dissertation 'supervision'. Learner-centred approaches consider post-graduate students' own initiative, passion, commitment and interest in the research problems they have identified for themselves. Dynamic facilitation emphasises the fact that post-graduate students are sources of original and alternative knowledge systems that supervisors have to 'recognize' and respect. As Vambe (2005: 291) argues elsewhere, part of this recognition involves allowing "an empowering assessment policy [that] welcomes innovation in which learners submit portfolios, projects and anecdotal records in which that constructed knowledge from their experience".

The second aspect is that dealing with post-graduate student researchers as critical thinkers on their own right has the potential to open up and validate the multiplicity of differently reflected interpretations of new or old research questions. In 
the 'knowledge economy' we live in, proponents of post-graduate dynamic supervision are required to constantly reflect on their achievements. This enables dynamic facilitation - as a living praxis - to challenge its previous ideological assumptions, and this can help to confront in fresh ways the necessity to identify, and mark out, what it is that supervision under conditions of distance of education learning can improve on, modify or even reject in the process of contributing to the field of education in general and distance education in particular. Expressed differently, in contrast to the principle of "learning by self discovery" that underscores dynamic facilitation, when the conceptual framework of research is dominated by the interests of the supervisors, their 'dominant discourse[s]...promote knowledges -outof-context and is further shaped by deficiency theorising'.(Bishop \& Glynn 1999: 177).

And, the third aspect is that, at an institutional level, the conditions of possibility of dynamic post-graduate supervision require a robust program of action in which leveraging systems of student support that help students to physically, and theoretically bridge the 'distance-ness' in distance education contexts be put in place. Thus, although in distance education research environments, the facilitator and the student are usually separated in space, the facilitator should not take a back seat or sit on the fence waiting for a whole year to pass without making efforts constantly engaging in critical dialogue with the facilitator. In the same vein, the dynamic facilitator cannot afford the luxury to sit back and not take the initiative to reach the student through telephone, e-mail, letters or even giving an invitation to meet face- toface with the student when the time is appropriate and convenient for both.

The situation where a student is assigned to a study advisor but the latter makes no effort to motivate or contact the student to work is a bad practice. Students may loose money paid to institutions of higher learning for a complete academic year without any progress- not even a discussion relating to the student's topic or proposal. This must be discouraged because it negatively impacts on throughput or completion rates and also puts the name of the institution into disrepute. It would however be re-imposing the 'domination' of the supervision process and reinstating the overall 'authority' of the dynamic study advisor or supervisor if it is left to him or her to check the progress of the student. The onus is squarely on the postgraduate student to maintain critical contacts with the facilitator.

Moreover, in the process of researching and writing up a postgraduate work, the student should constantly subject himself or herself to self-evaluation. One of the ways of doing this is to use a review instrument developed by the institution to measure the performance and verify whether or not the presentation of the researching findings are conforming to the agreed set standards. The National Association of Distance Education of South Africa (NADEOSA) has developed one such review instrument that contains the following aspects against which the student should measure his/her research progress;

- Language should be accessible and clear

- Self-assessment should include formative, summative and then integrated assessment.

- Layout and graphic design should conform to the departmental house style; it should pay attention to formal qualities of research presentation with agreed space and margins, headings and subheadings, use of adopted ways of referencing, font and table and graphics usage required (NADEOSA, 2004). 
University of South Africa's (UNISA) Institute of Curriculum Development (ICLD) has deepened the review instrument that should guide postgraduate students by including, inter alia,

- Context of study and its authenticity. This means research problems should be real-life problems, articulated through African indigenous knowledge perspectives.

- Content and theories used in postgraduate studies must enable postgraduate students to interrogate existing theories, or use a body of facts to generate alternative theoretical ways of explaining social reality.

- The transformative aspect of the postgraduate research should benefit from feedback from supervisors and peers.

- Assessment Design should include short written assignments, journals and portfolios developed alongside the main research (ICLD Review Instrument: 2007:1-12)

This instrument enables the postgraduate student to constantly benchmark the progress of the research process by remaining focused to the issues that make the research critically engaging, while aligning the presentation of the research output to the department and institutionally agreed format. These formalist aspects of dynamic supervision cannot be ignored; they constitute the core of research design.

Under dynamic facilitation as a paradigm for postgraduate supervision, the study advisor is committed to the work and shows interest in what the student is doing. Where a deadline passes without a student's response the supervisor contacts the student to find out about the latter's progress or problems and tries to provide support where necessary. Although the final product- dissertation- is the intellectual property of the student, it is the professional and moral responsibility of the facilitator to provide the necessary support and guidance for a successful completion of the dissertation. The supervisor who provides scaffolding and leverage support constantly to the student is in fact promoting good continual assessment practices during supervision. (Independent Examinations Board: 2006).

To realise the best practice in facilitating research in Distance Education environment we therefore argue that the dynamic facilitator or study advisor and the dynamic student post-graduate researcher in distance education environment should create a working 'contract'. In this contract both the facilitator and the supervised should set up deadlines as milestones they have promised to adhere to. If for example it is agreed that the first draft of the research proposal should be handed in within four months, this time frame must be respected. Some important support mechanisms that facilitators of research by dissertation in Distance Education may need includes: technical skills, writing skills, access to sources and resources, seminars, conferences and joint publication with student.

For best practice in facilitating postgraduate research work, facilitator should assist the student in technical aspects of the work such as making the research topic more focused and structuring the dissertation into both chapters and sub-topics. The facilitator should also guide the student to master technical skills of writing a dissertation e.g. referencing both in the text and in the bibliography.

Distance students writing graduate dissertation may need help in finding relevant sources to their work. The facilitator (study advisor) should support postgraduate students by taking them through the library to teach them where to get information or request for articles in relevant journals. The student should also be introduced to the subject librarian of his or her course. In most developing countries many students may have no access to the internet. It may be very useful for the 
supervisor to get some relevant sources from the internet or direct the student to such sources. Even relevant sources like the latest books that may be useful for the literature study should be mentioned to the student. To make students become more knowledgeable in the area of research seminars could be organised by the department for all graduate student students to read papers for their peers to review.

Postgraduate students in Open and Distance Learning environment should also be encouraged to attend conferences and present joint papers with their study advisors (facilitators) on areas that relate to their dissertations and or publish the papers in peer reviewed journals (Mthembu \& Naidoo, 2002). Such exposure and support mechanisms can motivate students to successfully complete their dissertations in time. This intervention in the supervision of postgraduate students introduces the 'formalist' type of supervision. The formalist type of supervision is an indispensable part of any supervision because however much students hold to their ideas passionately, these ideas can only be intelligible when presented in agreed formats (Mouton, 2004). But if promoters overemphasise this formatting dimension in supervision at the expense of the ideas and content of the research work, this may reduce supervision to an aesthetic game (Fisher) and thus rob the postgraduate research of its essence.

\section{Contribution of dynamic facilitation to Distance Education}

'Dynamic facilitation facilitation is a modest departure from traditional theories of supervising postgraduate students under conditions of distance education. As argued in this article the main tenets of this approach to supervision are that:

- Student researchers at postgraduate level need facilitators or study advisors who assist in creating optimum conditions for research

- Student researchers at postgraduate levels have the initiative to generate new forms of knowledge that can confirm but more importantly, interrogate existing perspectives.

- Student researchers at postgraduate levels are active and interactive in their learning as they should tolerate alternative perspectives from their peers and those who mentor them.

- Student researchers at postgraduate levels need certain learning infrastructure such as libraries and regular modes of access to their facilitators to be put in place. This is particularly important in a distance education context where this infrastructure is not assembled at a single spot.

In other words, the capacity of institutions to survive depend on their capacities to generate new knowledge that is relevant to the societies that must make full use of that knowledge. In order for this to happen, postgraduate research is a critical component for capacity building. This in turn is important for creating a critical mass of researchers who are conscious that there is nothing that can be called research for research's sake. Any research is purposive activity for the expansion of human knowledge. And in this process of generating knowledge, dynamic facilitation is crucial. It enables researchers to work with the best mentors. Conversely, it also enables supervisors to learn new knowledge from the supervised. All above, it enables the students who are researching to be independent thinkers. The notion of dynamic facilitation is thus preferable to the idea of 'supervision' that implies that the supervisor is an overseer, wielding power to pass or fail students. The contribution then, of dynamic facilitation is that it empowers the student researcher to think outside the prescribed box; the postgraduate student then becomes the subject of the research process. The young postgraduate researcher is afforded space to experiment with new 
and untried ideas. This should be the essence of postgraduate research and the focus of dynamic facilitation.

\section{Conclusion.}

In this paper we explored the possibility of evolving an alternative framework for supervising post-graduate students in the context of distance education. First, we showed the limitations of the AU Commission's Plan of Action for the Second decade of Education for Africa. Here, we noted with concern the absence of distance education as a significant area that also constitutes what is higher education in Africa. This silence, we attributed to the traditional theories of education that seem to have been developed with a residential university in mind. We then argued for the need to recognize distance education as a unique mode of delivery of education, requiring particular strategies to be used when supervising students enrolled in these institutions. The paper then proposed the framework of dynamic facilitation as promising to be the best practice to use when supervising postgraduate students within distance education environment. We demonstrated that dynamic facilitation takes into account the needs of distance education students. These needs relate to considering the distance between supervisors and students, the flexibility with which postgraduate students can conduct their research without feeling pressed for time. We noted that dynamic facilitation uses modes of self-evaluative assessment that can be built-into the main dissertation. We argued that journal of notes, and portfolio of the students' experiences during postgraduate research could be considered as part of the main dissertation during assessment by external examiners. Dynamic facilitation encourages supervisors to abate 'intellectual authority' on research topics so that postgraduate students can discover facts on their own, and critique received and canonized assumptions in traditional approaches to knowledge production. We concluded that in a context where the knowledge economy is under continual critical re-evaluation, it can no longer be 'business as usual' when it comes to the supervising of post-graduate students. In the context of distance learning, dynamic facilitation promises to be the best practice of scaffolding and leveraging student research work at the post graduate level because this type of supervision allows the student to relate research questions to social contexts and problems that they encounter in real life. Dynamic facilitation, thus, empowers students who are studying at a distance with the willpower to take decisions that affect their lives and studies.

\section{References}

African Union Commission. 2006. Plan of Action: The $2^{\text {nd }}$ Decade of Education for Africa (20062015). Addis Ababa, pp1-57.

Bishop, R. Glynn, T. 1999. Culture Counts: Changing Power Relations in Education. London \& New Jersey: ZED Books.

Butcher N. 2007. Harmonization of Higher Education Programmes in Africa: A Strategy for the African Union. Workshop held in Addis Ababa, Ethiopia, organised by the African Union on $6^{\text {th }}-7^{\text {th }}$ February. (Unpub): pp1-18.

Butcher N. 2007. "Developing an African Higher Education Quality Rating System" Workshop held in Accra, Ghana, $7^{\text {th }}-8^{\text {th }}$ May, and organised by the African Union Commission and Hosted by the Association of African Universities. (Unpub) pp1-97.

Confrey,J, 1990. What Constructivism implies for teaching. Journal for Research in Mathematics Education, Monograph 4: 107-122.

Criteria for Quality Distance Education in South Africa - 2003. A Revision of: Criteria for Quality Distance Education in South Africa: Draft Policy Statement, 1998. pp1-22.

Dembo, M H. 1994. Applying educational psychology. $5^{\text {th }}$ edition. London. Longman Ltd.

Flavel, JH. Miller, PH and Miller, SA. 1993. Cognitive Development. New Jersey. Prentice-Hall publishers Ltd. 
Independent Examination Board (IEB) 2006. "The Promotion of Good Assessment" Practices. Johannesburg. pp.1-4.

Institute for Curriculum and Learning Development (ICLD). 2007. ICLD Course Evaluation Instrument. UNISA. pp1-12.

Little W, Fowler, H. W.,Coulson, J. 1944. The Shorter Oxford English Dictionary on Historical Principles. Oxford: Clarendon Press (Third edition: (ed: C. T. Onions).

Mthembu T. \& Naidoo Prem. 2002. National Education's Research Benchmarks:

Realistic Targets or Pie in the Sky?. Alternation. Vol 9. no 1. pp.176-203.

NADEOSA. 2004. Criteria for the Review of Distance Education Materials Submitted for the NADEOSA Courseware Awards. Available online at:

http://www.nadeosa.org.za/Content/Activities/Detailed\%20Criteria.htm

Slavin, RE. 2006. Educational Psychology: Theory and Practice. New York. Pearson publishing Ltd.

Spener, D 1990. The Freirean Approach to Adult Literacy Education National Centre for ESL Literacy Education.

Suppes, P. 1974. The place of theory in educational research. Educational Researcher

Volume 3 Number $6: 3-10$.

Vambe M T. 2005.Opening and Transforming South African Education. Open Learning, Vol 20, no 3, November, pp.285-293.

Von Glaserfeld,E. 1992. A Constructivist's view of learning and teaching. In R, Duit, F, Golderg \& H. Niedderer(eds.) Research in Physics learning: Theoretical issues and empirical studies. Kiel.IPN ( Institute for Science Education).pages 30-37 